\title{
Pediatric High Flow Nasal Cannula Experience in a Tertiary Care Hospital in Saudi Arabia
}

\author{
Alayed Tareq ${ }^{1,}$,, Skaff Chahdah $^{2}$, Alabdulsalam Moath ${ }^{1}$, Alturki Abdullah ${ }^{1}$, Aljofan Fahad ${ }^{1}$, \\ Alanzi Fawaz ${ }^{1}$, Alofaisan Tareq ${ }^{1}$ \\ ${ }^{1}$ King Faisal Specialist Hospital and Research Center, Riyadh, Saudi Arabia \\ ${ }^{2}$ Dr. Sulaiman Alhabib Medical Group, Riyadh, Saudi Arabia
}

Email address:

tayaed@kfshrc.edu.sa (A. Tareq)

${ }^{*}$ Corresponding author

\section{To cite this article:}

Alayed Tareq, Skaff Chahdah, Alabdulsalam Moath, Alturki Abdullah, Aljofan Fahad, Alanzi Fawaz, Alofaisan Tareq. Pediatric High Flow Nasal Cannula Experience in a Tertiary Care Hospital in Saudi Arabia. American Journal of Pediatrics. Vol. 6, No. 3, 2020 , pp. $182-189$. doi: 10.11648/j.ajp.20200603.13

Received: March 15, 2020; Accepted: March 30, 2020; Published: May 12, 2020

\begin{abstract}
Acute respiratory failure, being a significant problem in Pediatric intensive care units, always requires support, whether via invasive or non-invasive devices. High flow nasal cannula, a relatively new machine, has multiple favorable physiological effects when used for respiratory distressed patients. It is currently widely applied in multiple settings, including PICU. This study describes the experience of HFNC use in a tertiary care hospital in Saudi Arabia. The primary outcome of interest was the intubation rate. The secondary outcomes were mortality rate and length of stay in the pediatric intensive care unit. Moreover, we compared these outcomes between two groups of patients: immunocompromised and immunocompetent patients. Four hundred thirteen patients were included. $45.5 \%$ admitted due to pneumonia. $24.6 \%$ of patients required intubation with an interval time between the initiation of HFNC and intubation being 40 hours (hrs.). The mortality rate was $17 \%$, and the mean length of stay in PICU was 12 days. One hundred thirty six (35\%) patients were immunocompromised. The majority admitted because of pneumonia (70\%). There was a significant statistical difference in the rate of intubation $(35.5 \%$ vs. $25 \%$, P-value 0.03 ) and mortality ( $39 \%$ vs. $5.5 \%$ with a p-value of $<0.0001$ ) between the two groups. However, when comparing the mortality rate in the immunocompromised patients only, $81.6 \%$ were intubated compared to $14.6 \%$ required only HFNC $(\mathrm{p}<0.05)$. HFNC seems to be beneficial and tolerable to pediatric populations. Although the immunocompromised patients showed expected higher mortality and intubation rate compared to the nonimmunocompromised, the sub-analysis showed that those who required only HFNC had a better survival rate.
\end{abstract}

Keywords: High Flow Nasal Cannula, Pediatric, PICU, Immunocompromised Patient

\section{Introduction}

Acute respiratory failure (ARF) is a fatal complication of various respiratory diseases requiring invasive mechanical ventilation. It is considered a major cause for Pediatric intensive care unit (PICU) admission.

High flow nasal cannula (HFNC) therapy is a noninvasive respiratory support that delivers a heated and humidified blend of air and oxygen through a nasal prong at a rate above or equal of $2 \mathrm{~L} / \mathrm{min}$ and provides continuous distending pressure [1].

It was first used in neonates and premature newborns [2].
For the last decades, it has been increasingly applied in PICU as respiratory support for children $[3,4]$.

HFNC has various physiological effects. It washouts pharyngeal dead space, reduces nasopharyngeal resistance, and generates positive expiratory pressure. Delivering humidified air provides better tolerance and comfort for the patients. In addition, using blended oxygen helps to control Fio2 delivery and mucociliary clearance [3-7].

Its common uses in pediatric include: acute viral bronchiolitis, asthma, post-extubation to avoid re-intubation, pneumonia, heart failure, neuromuscular diseases and recurrent apneic episodes [3, 4].

Barrezueta et al. performed a combined retrospective and 
prospective cohort study in NICU before and after the introduction of HFNC in patients with bronchiolitis. Fifty-six neonates were involved in each arm of the study. The main finding was a significant reduction in the use of noninvasive ventilation (NIV) after the use of HFNC and 2 patients required intubation in the pre-HFNC era while none after its use [8].

Two retrospective observational studies showed that HFNC decreased the intubation rate in infants less than 24 months of age admitted with viral bronchiolitis $[9,10]$.

Several studies were published aiming to assess the effect of HFNC use in the length of stay (LOS). Some showed no difference in LOS for children with bronchiolitis treated with HFNC compared to CPAP [11], while other studies did show a reduction in $\operatorname{LOS}[12,13]$. While in acute respiratory failure due to different diagnoses other than bronchiolitis in children, a retrospective study by Brink et al. showed no decrease in LOS using HFNC [14].

HFNC seems to be safe, but no clinical safety data is present. A case report was published describing severe air leak syndrome as a complication of HFNC use in 3 pediatric patients requiring intervention and escalation of respiratory support [15].

In adults, several studies were published about the use and efficacy of HFNC for multiple indications. Sztrymf et al. showed significant improvement in the respiratory status of $70 \%$ of adult patients admitted to ICU due to ARF using HFNC. It was associated with an early reduction of the respiratory rate (RR), heart rate (HR), dyspnea score, supraclavicular retraction, thoracoabdominal asynchrony, and better oxygenation. Absence of a significant decrease in the $\mathrm{RR}$, lower oxygenation, and persistence of thoracoabdominal asynchrony, after HFNC initiation, were early indicators of its failure [16].

In an Italian RCT [17], Maggiore et al. randomized 105 patients to receive either Venturi mask or HFNC as respiratory support post-extubation. It showed a significant reduction in the reintubation rate $(4 \%)$ in HFNC compared to $(21 \%)$ in the Venturi mask group. From the available literature, it can be affirmed that HFNC seems useful to treat and prevent post-extubation hypoxia in adults [1].

A multicenter open-label trial, FLORALI study published in 2015, showed that treatment with HFNC improved survival rate among patients with acute hypoxic respiratory failure; even though no difference in intubation rate between the study group and the control group who used standard oxygen treatment or NIV [18]. In a pragmatic open RCT in adults with hypoxia and tachypnea presented to a tertiary academic hospital ER in New Zealand, HFNC did not decrease the need for mechanical ventilation compared to standard oxygen therapy. Nevertheless, it was a safe therapy and might reduce the need for escalation of respiratory support within the first 24 hours of admission [19].

The effect of HFNC on the LOS in adult patients was conflicting in multiple studies. Nagata et al. compared the in- hospital mortality, ICU /hospital stay, and the need for invasive mechanical ventilation (IMV) pre-and-post HFNC era. Their study showed that the introduction of HFNC decreased ventilator use without affecting the mortality or ICU and hospital stay [7]. While Gaunt et al. reported that early use of HFNC is beneficial in both medical and trauma ICU with a decrease in ICU, hospital stay, and incidence of adverse events [20].

\section{Method}

Our study aims to describe the experience of the PICU unit in KFSH\&RC, Riyadh- Saudi Arabia, a tertiary care hospital with 18 beds and an average of 1000 admissions per year, in using HFNC.

All patients admitted to PICU, from the age of one week till the age of 14 years from the First of July 2014 until the end of February 2016, who required the use of HFNC, were collected. Patients started on HFNC due to increasing oxygen requirement and respiratory rate more than $2 \mathrm{SD}$ of their normal according to their age were included, while patients who required HFNC as a break from BIPAP were excluded.

Data was collected from Electronic Health Information Records by reviewing the variables from the day of starting the therapy until its discontinuation. Some patients had multiple sessions of therapy at the same admission. It was counted as one patient, and each session was included in the statistics. All data were kept confidential, and files were saved in a personal computer with a password.

Informed consent was waived due to the retrospective origin of the study.

\subsection{Outcome}

The primary outcome is the intubation rate. While the secondary outcome targeted the length of stay, duration of therapy, and mortality rate in PICU. The use of sedation, inotropic supports, and complication rates were included. These were compared between two groups of patients: immunocompromised and immunocompetent group. We defined the immunocompromised group as the group of patients who has hematological/oncological, immunodeficiency diseases, or who underwent bone marrow transplant. Also, the change in the physiologic parameters over 2 hours from the start of HFNC were collected and analyzed.

\subsection{Statistical Analysis}

Mean with standard deviation and percentage were calculated for continuous and categorical variables. For this retrospective study, all statistical analysis of data was done using the SAS software package, version 9.4 (Statistical Analysis System, SAS Institute Inc., Cary, NC, USA).

Descriptive statistics for the continuous variables were reported as mean, and categorical variables were summarized as frequencies and percentages.

Continuous variables were compared by independent 
Student's t-test or ANOVA, while the Chi-square test compared categorical variables.

The level of significance was set at $p$-value $<0.05$.

\section{Results}

\subsection{Subject Characteristics}

Total Patients admitted to KFSH\&RC from July-2014 to February 2016 were 1459. Four hundred thirteen patients (28.3\%) required HFNC during any time of their admission period. Twenty-two cases were excluded from the study since the use of HFNC was a break from BIPAP. Sixty-three $(5.3 \%)$ patients required multiple episodes of HFNC during their admission to PICU. They were weaned gradually to low flow nasal cannula. Later on, they required to resume HFNC. The decision was made by the treating physician depending on the clinical situation of the child.

Patients' demographics are summarized in table [1]. Surprisingly, 363 of HFNC patients $(93 \%)$ were female. The average age of the patients was 33.3 months $(0.5-168 \mathrm{~m})$, and their average weight was $10 \mathrm{Kg}(2-61 \mathrm{Kg})$.

The majority of the admitted patients were from the inpatients' floor (193, 49.3\%), followed by the Emergency department $(65,16 \%)$. (table 1$)$

Table 1. Demographic characteristics.

\begin{tabular}{lll}
\hline \multicolumn{2}{l}{ Demographic characteristic } & \\
\hline Gender & N & \% \\
\hline Male & 28 & $7.1 \%$ \\
Female & 363 & $92.8 \%$ \\
Ambiguous & 1 & $0.25 \%$ \\
Total & 391 & \\
\hline
\end{tabular}

\begin{tabular}{lll}
\hline & Mean & Range \\
\hline Age (month) & 33.3 & $0.5-168$ \\
Weight (Kilogram) & 10 & $2-61$ \\
Admission area & $\mathrm{N}$ & $\%$ \\
Inpatient floor & 193 & 49.3 \\
Emergency Room & 65 & 16.6 \\
Operating room & 63 & 16.1 \\
Outside Admission & 58 & 14.8 \\
Outpatient Suite & 12 & 3.00 \\
\hline
\end{tabular}

Table 2. Primary disease.

\begin{tabular}{lll}
\hline Primary disease & N & \% \\
\hline Cardiac disease & 106 & 27.11 \\
Post BMT & 74 & 18.92 \\
Hematology and Oncology & 42 & 10.74 \\
Metabolic and genetic disease & 37 & 9.46 \\
GIT and liver disease & 35 & 8.95 \\
Neurological disease & 29 & 7.41 \\
Immunodeficiency & 20 & 5.11 \\
Respiratory disease + Airway & 17 & 4.34 \\
Solid-organ transplant & 6 & 1.53 \\
Others (preterm / rena 1/ endocrine / rheumatology / & 25 & 6.39 \\
accident / orthopedic) & & \\
\hline
\end{tabular}

Table 3. Reason for PICU admission.

\begin{tabular}{lll}
\hline Reason for PICU admission & N & \% \\
\hline Pneumonia & 178 & 45.52 \\
Post Surgery & 63 & 16.11 \\
Cardiac causes ( heart failure / congenital heart disease) & 46 & 11.76 \\
Post cardiac surgery & 25 & 6.39 \\
Non-infectious pulmonary cause & 20 & 5.12 \\
Sepsis and septic shock & 13 & 3.32 \\
Bronchiolitis & 5 & 1.28 \\
Others & 41 & 10.49 \\
\hline
\end{tabular}

The most common cause of PICU admission was pneumonia $(178,45.5 \%)$, followed by Post-surgical patients (63, 16\%) (Table 3). Pneumonia was the most common reason to initiate therapy $(185,38 \%)$. During the period study, $666(45.6 \%)$ patients were ventilated, and 150 $(22.5 \%)$ were extubated directly to HFNC. These patients contributed to $29 \%$ of the studied group. (table 4 ).

Table 4. Reason for HFNC.

\begin{tabular}{lll}
\hline Reason for HFNC & N 488 & \% \\
\hline Pneumonia (n all) & 185 & 37.91 \\
Post first extubation & 142 & 29.09 \\
Non-infectious lung disease & 69 & 14.14 \\
Increase WOB after extubation & 25 & 5.12 \\
Cardiac causes & 17 & 3.48 \\
Post NIV & 16 & 3.28 \\
Airway disease & 10 & 2.05 \\
Post second extubation & 8 & 1.64 \\
Bronchiolitis & 6 & 1.23 \\
Septic shock & 6 & 1.23 \\
Others & 4 & 0.82 \\
\hline
\end{tabular}

There was a wide variation in the primary diagnosis among patients. Cardiac diseases, whether structural anomalies or heart failure, were the most common primary diagnosis $(106,27 \%)$ followed by post bone marrow transplant (BMT) and Hematology/oncology patients $(74,19 \%$ and $42,11 \%$ respectively) (Table 2$)$. Total immunocompromised patients were 136 (35\%).

\subsection{Primary Outcome}

In our retrospective study, we considered the requirement of intubation to be the primary outcome. One hundred twenty patients $(24.6 \%)$ required escalation to invasive ventilation. The time interval between the initiation of therapy to intubation was $40 \mathrm{hrs}$ (1- $302 \mathrm{hrs})$.

The total number of patients requiring escalation of therapy either to invasive or noninvasive ventilation was 152 (31.1\%).

\subsection{Secondary Outcome}

The average length of stay in PICU for patients treated with HFNC was 12 days (1-139 days). While the mortality rate was $17.1 \%$ (67 patients).

We also studied the physiological parameters (heart rate, respiratory rate, saturation, and blood pressure) at the time of 
starting HFNC and 2 hours after. There was a significant improvement in heart rate, respiratory rate, and saturation after 2 hours from starting HFNC ( $\mathrm{P}$ values $<0.0001$, $<0.0001,0.0405$, respectively), but there was no significant difference in the blood pressure (P-value 0.0673).

The mean $\mathrm{PH}$ at the start of HFNC was 7.37, compared to 7.55 after 2 hours of therapy (P-value of 0.3 ). Similarly, there was no significant statistical difference in the $\mathrm{Pco} 2$ value (6.78 vs. $6.8 \mathrm{Kpa}$, P-value of 0.88 ).

We aimed to review the two most common reported complications with HFNC, nasal trauma (bleeding or irritation) [21], and air leak syndrome based on radiological evidence (pneumothorax, subcutaneous emphysema, and pneumopericardium) $[15,22]$.

Twenty-nine $(6 \%)$ of the patients suffered from one of these complications. Nasal bleeding was the most common and occurred in $18(3.7 \%)$ patients, while air leak syndrome occurred only in $10(2 \%)$ patients.

The delivered high flow might be unpleasant for most children as they need time for adjustment. To improve tolerance, sedations were utilized in a group of patients. Our review showed that $205(42 \%)$ patients were on sedation during the HFNC. Almost half of the patients required sedative agents were post extubation children. That could be explained by the use of multiple regimens for withdrawal syndrome. Dexmedetomidine, lorazepam, and chloral hydrate, as needed, were the most commonly used agents.

No major hemodynamic instability was noticed during the use of HFNC. Sixty-three (13\%) patients were on inotropic support while on HFNC. Half of the patients requiring inotropes were cardiac patients due to either heart failure and cardiogenic shock or post congenital heart surgery, while 22 (34\%) patients on inotropes were diagnosed with septic shock.

Over one-third of the total patients $(35 \%, n=136)$ were immunocompromised. The majority was post-BMT (74, $54 \%$ ), followed by hemato-oncology $(42,31 \%)$ and primary immunodeficiency $(20,15 \%)$ patients.

Most of them were admitted to the PICU due to pneumonia $(95,70 \%)$, which was as well the most common reason for initiating $\operatorname{HFNC}(93,67.4 \%)$.

Not surprisingly, intubation rate in immunocompromised children was significantly higher than immunocompetent patients $(49,35.5 \%$ vs $87,25 \%$, P-value $=0.0314)$. The time interval between initiating HFNC and escalating the therapy to invasive support was 5 hours earlier in the immunocompromised group compared to the immunocompetent group (31.72 hrs. vs. $36.48 \mathrm{hrs}$.)

Immunocompromised patients had longer stay in PICU and higher mortality rate compared to nonimmunocompromised patients (14.7 days vs 11 days) and $(53,39 \%$ vs $14,5.5 \%$, P-value $<0.0001)$ respectively.

Even more, those patients had higher complication rate compared to the others $(16,11.6 \%$ vs $13,3.7 \%$, P-value < $0.0019)$. One patient suffered from both complications, while 3 (18.75\%) developed air leak syndrome, and 12 (75\%) patients complained of nasal irritation or bleeding.
Interestingly, the requirement of inotropic support was less in the immunocompromised group $(10,7.25 \%$ vs. 53, $15.15 \%, \mathrm{P}$ value 0.0283 ). Since half of the patients requiring inotropes were cardiac patients, it could explain the finding mentioned above. There was no statistical difference in the requirement of sedation between both groups (56, 40.6\% vs. 148, 42.3\%, P-value 0.8086).

A small sub-analysis was done in the immunocompromised group and showed that 49 (35.5\%) patients required to be intubated compared to 89 (64.5\%) who required only HFNC during their stay in PICU. The total mortality rate was 39\% (53 patients).

Forty $(81.6 \%)$ patients from the intubated group died compared to $13(14.6 \%)$ in the non-intubated group (P-value $<0.05$ ). It is worth to mention that 11 patients from the latter group were signed Do Not Resuscitate (DNR).

\section{Discussion}

Respiratory support is the most common intervention provided in any pediatric intensive care unit. High flow nasal cannula, a relatively new device in many ICUs, was first introduced to neonates as an alternative to nasal continuous positive airway pressure (nCPAP) (2). No specific definition has yet been established for HFNC. It has been described as a device that delivers a humidified, heated and blended mixture of air and oxygen at high flow matching the patient's high inspiratory flow during a respiratory distress event $[4,15,23$ 25].

A flow higher than 2 liters per minute (lpm) in the neonate and $>6 \mathrm{lpm}$ in children are considered high flow $[1,26]$. The recommended flow in pediatric is $2 \mathrm{~L} / \mathrm{kg} /$ minute $[27,28]$, higher than that did not show a significant difference in clinical outcome; it instead showed more discomfort and a more extended stay in PICU [27].

High flow nasal cannula has many suggested mechanisms through which it affects the respiratory system. Nasopharyngeal dead space washout does improve both ventilation and oxygenation [5, 29]. More Fio2 will be available for the patient to inspire in each breath, and it can be titrated to the patient's need [30]. This advantage is particularly important in neonates and children who have larger anatomic dead space compared to adults [31]. By delivering a high flow that matches or exceeds the patient's peak inspiratory flow, the inspiratory resistance will decrease and will subsequently help in the work of breathing. In addition, the high flow generates a distending pressure that will help in recruiting alveoli and improve respiratory distress. It will increase the pressure generated during the expiratory phase of the respiratory cycle, which will be transmitted down the airways to the alveoli and open the atelectasis [32]. A flow $\geq 2 \mathrm{~L} / \mathrm{Kg} / \mathrm{Min}$ can generate a PEEP of $\geq 4 \mathrm{cmH} 2 \mathrm{O}$ [33]. However, many factors play a role in the degree and maintenance of the generated pressure. The leak around the nasal prong and from the mouth affects the sustainability of the pressure [33-35].

The primary characteristic of the high flow nasal cannula 
is the delivery of a gas mixture that is heated to around 37 degrees and humidified up to $100 \%$ to the upper airway [29]. This provides many potentials. It decreases the injury to the respiratory epithelial cells, preserves its function, and decreases inflammation [36]. It also maintains and improves the mucociliary lung clearance [37], prevents the nasopharyngeal bronchoconstriction reflex [38], improves lung compliance, and decreases mouth dryness which increases its tolerability by the patients [5].

Over the last decades, published studies have shown the vast varieties of diseases and conditions for which high flow nasal cannula can be used [4, 5, 20, 22, 39].

Bronchiolitis has been the most studied disease for the use of HFNC in pediatric [5]. In our retrospective observational study, we showed that HFNC could be used in many conditions. Pneumonia (38\%), followed by post-extubation $(29 \%)$ were the two most common causes.

Regarding the primary outcome, our study showed that the rate of intubation was around $25 \%$. While the overall escalation of therapy (invasive and noninvasive) was $31.1 \%$. $2.66 \%$ was not intubated because of their Do Not Resuscitate status, and HFNC was used as palliative therapy. In a retrospective study, McKiernan et al. compared the intubation rate between two eras: before and after the introduction of HFNC. It showed a $68 \%$ reduction of intubation in infants admitted to PICU with bronchiolitis [10]. Schibler et al. conducted a retrospective analysis in all infants admitted to PICU, requiring HFNC between 2005 and 2009 , showed an overall reduction in the intubation rate to $7 \%$ compared to their local registry [9]. When comparing HFNC to noninvasive ventilation in post extubated infants who underwent congenital heart surgery, there was no statistical difference in the reintubation rate [40]. In adults, a multicenter randomized control trial was conducted in adult patients admitted to ICU with hypoxic respiratory failure. It compared the rate of intubation among patients receiving conventional oxygen therapy, HFNC, and NIV. It showed no significant difference in the outcome, but showed significant 90 days mortality reduction in the group treated with HFNC [40]. A meta-analysis done by Zhao, $\mathrm{H}$ et al. comparing HFNC with conventional oxygen therapy and NIV, showed that HFNC is associated with a reduction in intubation rate when compared to conventional oxygen therapy (COT) but not to noninvasive ventilation (NIV) [41]. Our study might have shown a higher than expected intubation rate, and this could be related to our patient population since 35\% were immunocompromised.

Regarding the mortality rate after the introduction of HFNC in adult, a recent systemic review and meta-analysis was done by Rochwerg. B et al. showed no reduction in mortality rate when comparing HFNC with COT. It also concluded that no statistical difference in the length of stay in ICU [42]. In pediatrics, there is scarcity in the studies assessing the benefit of HFNC in mortality rate and PICU length of stay. Some of the studies showed that HFNC does not reduce PICU LOS when compared to the time before its use $[8,9]$. While others showed a significant reduction in
PICU length of stay (LOS) $[10,13]$. In this study, 17\% was the mortality rate among patients requiring HFNC, and the average LOS was around 12 days.

The use of HFNC is effective in reducing the work of breathing and improving many physiological parameters. Many studies showed the benefit of HFNC in reducing heart rate, respiratory rate, and increasing oxygenation and saturation [8-10, 43]. Most of the studies showed improvement after 60 to 90 minutes from starting the intervention [43, 44]. Our study showed similar results. There was a significant statistical difference in heart rate, respiratory rate, and saturation within 2 hours from starting HFNC, but this was not observed for the blood pressure readings. On the other hand, few studies showed significant statistical improvement in blood gas parameters: $\mathrm{PH}$ and $\mathrm{PaCO} 2$ [43], while others did not reach a statistically significant difference [45]. We showed no significant difference in blood gas parameters before and after HFNC. This could indicate that the response to HFNC should be followed mainly by physical improvement followed by blood gas as an adjunct parameter since these factors are the main ones that predict HFNC failure and the need to escalate therapy. Studies have shown that failure to reduce respiratory rate and high pco2 at the start of therapy is indicative of therapy futility [43].

HFNC has been reported to be well tolerated by the pediatric populations with minimal complications. It has been preferred over CPAP since it causes less nasal trauma [21]. In our study, only $3.7 \%$ of the patients showed minimal nasal bleeding. On the other hand, only $2 \%$ of our studied patients developed pneumothorax. Fortunately, air leak syndrome is not a common problem in patients using HFNC and has been reported in a few studies $[15,22]$.

Immunocompromised patients are a unique subgroup of patients, due to their different response to various diseases, since their immunity is dysregulated. Respiratory failure was the most common reason for PICU admission [46]. This group of patients is known to have a high mortality rate, especially when admitted to PICU, which approaches $20 \%$ and will increase up to $42 \%$ if the patient requires intubation [47] and might even reach up to $60 \%$ [48]. So, whether avoiding intubation in these patients and initiating another noninvasive respiratory support would decrease their mortality rate is not yet approved. Some studies showed the benefit of NIV with a success rate of $74.2 \%$ and a decrease in the mortality among pediatric patients with malignancy [49]. Nevertheless, in a recent RCT, the early application of CPAP showed a higher PICU mortality rate [50]. After introducing HFNC and proving its benefit, many adult studies were published comparing HFNC, NIV, and conventional oxygen therapy in immunocompromised patients. Two studies showed the superiority of HFNC over NIV in both intubation and mortality rates $[51,52]$. While others showed no extra benefit of HFNC when compared to COT $[51,53]$. This is why no recommendation can be made to prefer a device over another. An important question arises when using these noninvasive devices: when is the appropriate time to consider 
invasive ventilation? Until now, no definitive answer is reached, but most agree that delaying intubation is a risk factor for increasing mortality $[54,55]$. In our study, onethird of our patients were immunocompromised; most of them (54.4\%) were post bone marrow transplant. Most of the admissions were due to respiratory causes (70\%). We showed that there was a significant statistical difference in both intubation and mortality rates between the two groups. The interval time between initiating the HFNC and the decision to intubate was lower in the immunocompromised group by almost 5 hours. Despite that, they had a higher mortality rate (39\%). In a sub-analysis done comparing the mortality rate between the immunocompromised group who required intubation and those maintained on HFNC only, it showed a higher mortality rate in the first group compared to the latter. This is consistent with most of the studies that showed a higher mortality rate in intubated immunocompromised patients $[52,56]$.

\section{Limitation}

Our study is a retrospective study. It was conducted in a single center. We did not include the $\mathrm{PaO} 2 / \mathrm{FiO} 2$ ratio and a severity scoring system to classify the severity of the patient's illnesses.

However, our study includes a significantly large number of immunocompromised patients and showed that this subgroup is more vulnerable and has a higher risk of intubation and mortality compared to the other group. This would open for more studies including these patients and stratifying their risk factors and direct causes of mortality.

\section{Conclusion}

This study showed that HFNC might be beneficial in pediatrics by reducing the rate of intubation and improving survival rate. HFNC is a well-tolerated device and could be considered as an initial respiratory support delivered to pediatrics in PICU.

Immunocompromised patients are different since higher intubation, and mortality rates were noticed when compared to immunocompetent patients. Nevertheless, when comparing the mortality rate among the immunocompromised patients who required intubation versus those who maintained on HFNC, it showed a higher survival rate in the latter group. This cannot be generalized to this subgroup of patients since many other factors do contribute to their already high mortality rate.

\section{References}

[1] Mayfield S, Jauncey-Cooke J, Hough JL, Schibler A, Gibbons $\mathrm{K}$, Bogossian F. High-flow nasal cannula therapy for respiratory support in children. Cochrane Database of Systematic Reviews. 2014 (3).

[2] Wilkinson D, Andersen C, O'Donnell CP, De Paoli AG, Manley BJ. High flow nasal cannula for respiratory support in preterm infants. Cochrane Database Syst Rev. 2016; 2:

\section{CD006405.}

[3] Ramnarayan P, Schibler A. Glass half empty or half full? The story of high-flow nasal cannula therapy in critically ill children. Intensive Care Med. 2017; 43 (2): 246-9.

[4] Milési C, Boubal M, Jacquot A, Baleine J, Durand S, Odena MP, et al. High-flow nasal cannula: recommendations for daily practice in pediatrics. Annals of intensive care. 2014; 4: 29.

[5] Gotera C, Diaz Lobato S, Pinto T, Winck JC. Clinical evidence on high flow oxygen therapy and active humidification in adults. Rev Port Pneumol. 2013; 19 (5): 217-27.

[6] Vargas F, Saint-Leger M, Boyer A, Bui NH, Hilbert G. Physiologic Effects of High-Flow Nasal Cannula Oxygen in Critical Care Subjects. Respir Care. 2015; 60 (10): 1369-76.

[7] Nagata K, Morimoto T, Fujimoto D, Otoshi T, Nakagawa A, Otsuka K, et al. Efficacy of High-Flow Nasal Cannula Therapy in Acute Hypoxemic Respiratory Failure: Decreased Use of Mechanical Ventilation. Respir Care. 2015; 60 (10): 1390-6.

[8] Bermudez Barrezueta L, Garcia Carbonell N, Lopez Montes J, Gomez Zafra R, Marin Reina P, Herrmannova J, et al. [High flow nasal cannula oxygen therapy in the treatment of acute bronchiolitis in neonates]. An Pediatr (Barc). 2017; 86 (1): 3744.

[9] Schibler A, Pham TM, Dunster KR, Foster K, Barlow A, Gibbons $\mathrm{K}$, et al. Reduced intubation rates for infants after introduction of high-flow nasal prong oxygen delivery. Intensive Care Med. 2011; 37 (5): 847-52.

[10] McKiernan C, Chua LC, Visintainer PF, Allen H. High Flow Nasal Cannulae Therapy in Infants with Bronchiolitis. The Journal of Pediatrics. 2010; 156 (4): 634-8.

[11] Metge P, Grimaldi C, Hassid S, Thomachot L, Loundou A, Martin $\mathrm{C}$, et al. Comparison of a high-flow humidified nasal cannula to nasal continuous positive airway pressure in children with acute bronchiolitis: experience in a pediatric intensive care unit. Eur J Pediatr. 2014; 173 (7): 953-8.

[12] Riese J, Fierce J, Riese A, Alverson BK. Effect of a Hospitalwide High-Flow Nasal Cannula Protocol on Clinical Outcomes and Resource Utilization of Bronchiolitis Patients Admitted to the PICU. Hosp Pediatr. 2015; 5 (12): 613-8.

[13] Milani GP, Plebani AM, Arturi E, Brusa D, Esposito S, Dell'Era L, et al. Using a high-flow nasal cannula provided superior results to low-flow oxygen delivery in moderate to severe bronchiolitis. Acta Paediatr. 2016; 105 (8): e368-72.

[14] ten Brink F, Duke T, Evans J. High-flow nasal prong oxygen therapy or nasopharyngeal continuous positive airway pressure for children with moderate-to-severe respiratory distress?*. Pediatr Crit Care Med. 2013; 14 (7): e326-31.

[15] Hegde S, Prodhan P. Serious air leak syndrome complicating high-flow nasal cannula therapy: a report of 3 cases. Pediatrics. 2013; 131 (3): e939-44.

[16] Sztrymf B, Messika J, Mayot T, Lenglet H, Dreyfuss D, Ricard JD. Impact of high-flow nasal cannula oxygen therapy on intensive care unit patients with acute respiratory failure: a prospective observational study. J Crit Care. 2012; 27 (3): 324 e9-13. 
[17] Maggiore SM, Idone FA, Vaschetto R, Festa R, Cataldo A, Antonicelli $F$, et al. Nasal high-flow versus Venturi mask oxygen therapy after extubation. Effects on oxygenation, comfort, and clinical outcome. Am J Respir Crit Care Med. 2014; 190 (3): 282-8.

[18] Frat JP, Thille AW, Mercat A, Girault C, Ragot S, Perbet S, et al. High-flow oxygen through nasal cannula in acute hypoxemic respiratory failure. N Engl J Med. 2015; 372 (23): 2185-96.

[19] Jones PG, Kamona S, Doran O, Sawtell F, Wilsher M. Randomized Controlled Trial of Humidified High-Flow Nasal Oxygen for Acute Respiratory Distress in the Emergency Department: The HOT-ER Study. Respir Care. 2016; 61 (3): 291-9.

[20] Gaunt KA, Spilman SK, Halub ME, Jackson JA, Lamb KD, Sahr SM. High-Flow Nasal Cannula in a Mixed Adult ICU. Respir Care. 2015; 60 (10): 1383-9.

[21] Collins CL, Holberton JR, Barfield C, Davis PG. A randomized controlled trial to compare heated humidified high-flow nasal cannulae with nasal continuous positive airway pressure postextubation in premature infants. J Pediatr. 2013; 162 (5): 949-54 e1.

[22] Wing R, James C, Maranda LS, Armsby CC. Use of HighFlow Nasal Cannula Support in the Emergency Department Reduces the Need for Intubation in Pediatric Acute Respiratory Insufficiency. Pediatric Emergency Care. 2012; 28 (11): 1117-23.

[23] Testa G, Iodice F, Ricci Z, Vitale V, De Razza F, Haiberger R, et al. Comparative evaluation of high-flow nasal cannula and conventional oxygen therapy in paediatric cardiac surgical patients: a randomized controlled trial. Interact Cardiovasc Thorac Surg. 2014; 19 (3): 456-61.

[24] Mikalsen IB, Davis P, Oymar K. High flow nasal cannula in children: a literature review. Scand J Trauma Resusc Emerg Med. 2016; 24: 93.

[25] Miller AG, Gentle MA, Tyler LM, Napolitano N. High-Flow Nasal Cannula in Pediatric Patients: A Survey of Clinical Practice. Respir Care. 2018; 63 (7): 894-9.

[26] Lee JH, Rehder KJ, Williford L, Cheifetz IM, Turner DA. Use of high flow nasal cannula in critically ill infants, children, and adults: a critical review of the literature. Intensive Care Med. 2013; 39 (2): 247-57.

[27] Milesi C, Pierre AF, Deho A, Pouyau R, Liet JM, Guillot C, et al. A multicenter randomized controlled trial of a $3-\mathrm{L} / \mathrm{kg} / \mathrm{min}$ versus $2-\mathrm{L} / \mathrm{kg} / \mathrm{min}$ high-flow nasal cannula flow rate in young infants with severe viral bronchiolitis (TRAMONTANE 2). Intensive Care Med. 2018; 44 (11): 1870-8.

[28] Hough JL, Pham TM, Schibler A. Physiologic effect of highflow nasal cannula in infants with bronchiolitis. Pediatr Crit Care Med. 2014; 15 (5): e214-9.

[29] Dysart K, Miller TL, Wolfson MR, Shaffer TH. Research in high flow therapy: mechanisms of action. Respir Med. 2009; 103 (10): 1400-5.

[30] Wettstein RB, Shelledy DC, Peters JI. Delivered Oxygen Concentrations Using Low-Flow and High-Flow Nasal Cannulas. Respiratory Care. 2005; 50 (5): 604-9.

[31] Numa AH, Newth CJ. Anatomic dead space in infants and children. J Appl Physiol (1985). 1996; 80 (5): 1485-9.
[32] Parke RL, McGuinness SP. Pressures delivered by nasal high flow oxygen during all phases of the respiratory cycle. Respir Care. 2013; 58 (10): 1621-4.

[33] Milesi C, Baleine J, Matecki S, Durand S, Combes C, Novais $\mathrm{AR}$, et al. Is treatment with a high flow nasal cannula effective in acute viral bronchiolitis? A physiologic study. Intensive Care Med. 2013; 39 (6): 1088-94.

[34] Sivieri EM, Gerdes JS, Abbasi S. Effect of HFNC flow rate, cannula size, and nares diameter on generated airway pressures: an in vitro study. Pediatr Pulmonol. 2013; 48 (5): 506-14.

[35] Hasan RA, Habib RH. Effects of flow rate and airleak at the nares and mouth opening on positive distending pressure delivery using commercially available high-flow nasal cannula systems: a lung model study. Pediatr Crit Care Med. 2011; 12 (1): e29-33.

[36] Chidekel A, Zhu Y, Wang J, Mosko JJ, Rodriguez E, Shaffer TH. The effects of gas humidification with high-flow nasal cannula on cultured human airway epithelial cells. Pulm Med. 2012; 2012: 380686.

[37] Hasani A, Chapman T, McCool D, Smith R, Dilworth J, Agnew J. Domiciliary humidification improves lung mucociliary clearance in patients with bronchiectasis. Chronic Respiratory Disease. 2008; 5 (2): 81-6.

[38] Fontanari P, Burnet H, Zattara-Hartmann MC, Jammes Y. Changes in airway resistance induced by nasal inhalation of cold dry, dry, or moist air in normal individuals. Journal of Applied Physiology. 1996; 81 (4): 1739-43.

[39] Rubin S, Ghuman A, Deakers T, Khemani R, Ross P, Newth CJ. Effort of breathing in children receiving high-flow nasal cannula. Pediatr Crit Care Med. 2014; 15 (1): 1-6.

[40] Richter RP, Alten JA, King RW, Gans AD, Rahman AF, Kalra Y, et al. Positive Airway Pressure Versus High-Flow Nasal Cannula for Prevention of Extubation Failure in Infants After Congenital Heart Surgery. Pediatr Crit Care Med. 2019; 20 (2): $149-57$

[41] Zhao H, Wang H, Sun F, Lyu S, An Y. High-flow nasal cannula oxygen therapy is superior to conventional oxygen therapy but not to noninvasive mechanical ventilation on intubation rate: a systematic review and meta-analysis. Crit Care. 2017; 21 (1): 184.

[42] Rochwerg B, Granton D, Wang DX, Helviz Y, Einav S, Frat JP, et al. High flow nasal cannula compared with conventional oxygen therapy for acute hypoxemic respiratory failure: a systematic review and meta-analysis. Intensive Care Med. 2019; 45 (5): 563-72.

[43] Abboud PA, Roth PJ, Skiles CL, Stolfi A, Rowin ME. Predictors of failure in infants with viral bronchiolitis treated with high-flow, high-humidity nasal cannula therapy*. Pediatr Crit Care Med. 2012; 13 (6): e343-9.

[44] Spentzas T, Minarik M, Patters AB, Vinson B, Stidham G. Children with respiratory distress treated with high-flow nasal cannula. J Intensive Care Med. 2009; 24 (5): 323-8.

[45] Sztrymf B, Messika J, Bertrand F, Hurel D, Leon R, Dreyfuss $\mathrm{D}$, et al. Beneficial effects of humidified high flow nasal oxygen in critical care patients: a prospective pilot study. Intensive Care Med. 2011; 37 (11): 1780-6. 
[46] Demaret P, Pettersen G, Hubert P, Teira P, Emeriaud G. The critically-ill pediatric hemato-oncology patient: epidemiology, management, and strategy of transfer to the pediatric intensive care unit. Ann Intensive Care. 2012; 2 (1): 14.

[47] Zinter MS, Dvorak CC, Spicer A, Cowan MJ, Sapru A. New Insights Into Multicenter PICU Mortality Among Pediatric Hematopoietic Stem Cell Transplant Patients. Crit Care Med. 2015; 43 (9): 1986-94.

[48] Rowan CM, McArthur J, Hsing DD, Gertz SJ, Smith LS, Loomis A, et al. Acute Respiratory Failure in Pediatric Hematopoietic Cell Transplantation: A Multicenter Study. Crit Care Med. 2018; 46 (10): e967-e74.

[49] Pancera CF, Hayashi M, Fregnani JH, Negri EM, Deheinzelin D, de Camargo B. Noninvasive Ventilation in Immunocompromised Pediatric Patients: Eight Years of Experience in a Pediatric Oncology Intensive Care Unit. Journal of Pediatric Hematology/Oncology. 2008; 30 (7): 5338.

[50] Peters MJ, Agbeko R, Davis P, Klein N, Zenasni Z, Jones A, et al. Randomized Study of Early Continuous Positive Airways Pressure in Acute Respiratory Failure in Children With Impaired Immunity (SCARF) ISRCTN82853500. Pediatr Crit Care Med. 2018; 19 (10): 939-48.

[51] Frat J-P, Ragot S, Girault C, Perbet S, Prat G, Boulain T, et al. Effect of non-invasive oxygenation strategies in immunocompromised patients with severe acute respiratory failure: a post-hoc analysis of a randomised trial. The Lancet Respiratory Medicine. 2016; 4 (8): 646-52.

[52] Coudroy R, Jamet A, Petua P, Robert R, Frat JP, Thille AW. High-flow nasal cannula oxygen therapy versus noninvasive ventilation in immunocompromised patients with acute respiratory failure: an observational cohort study. Ann Intensive Care. 2016; 6 (1): 45.

[53] Azoulay E, Lemiale V, Mokart D, Nseir S, Argaud L, Pene F, et al. Effect of High-Flow Nasal Oxygen vs Standard Oxygen on 28-Day Mortality in Immunocompromised Patients With Acute Respiratory Failure: The HIGH Randomized Clinical Trial. JAMA. 2018; 320 (20): 2099-107.

[54] Rowan CM, Gertz SJ, McArthur J, Fitzgerald JC, Nitu ME, Loomis A, et al. Invasive Mechanical Ventilation and Mortality in Pediatric Hematopoietic Stem Cell Transplantation: A Multicenter Study. Pediatr Crit Care Med. 2016; 17 (4): 294-302.

[55] Depuydt PO, Benoit DD, Vandewoude KH, Decruyenaere JM, Colardyn FA. Outcome in Noninvasively and Invasively Ventilated Hematologic Patients With Acute Respiratory Failure. CHEST. 2004; 126 (4): 1299-306.

[56] Cortegiani A, Madotto F, Gregoretti C, Bellani G, Laffey JG, Pham $\mathrm{T}$, et al. Immunocompromised patients with acute respiratory distress syndrome: secondary analysis of the LUNG SAFE database. Crit Care. 2018; 22 (1): 157. 